\title{
O que toda professora e todo professor de português precisam saber
}

\section{What every Portuguese teacher needs to know}

\author{
Luciano Amaral Oliveira ${ }^{1}$
}

Resumo: Este texto é resultante da conferência intitulada $O$ que toda professora e todo professor de português precisam saber, proferida no VIII Encontro de Sociolinguística - variação e ensino: unidade e diversidade, realizado na Universidade Estadual da Bahia, Campus I, em julho de 2018. Trato aqui de questões teóricas incontornáveis para docentes de língua portuguesa, as quais partem da seguinte assertiva: não existem práticas pedagógicas sem teorias. $\mathrm{O}$ objetivo deste texto é compartilhar, com leitoras e leitores, algumas reflexões sobre a importância de se ter consciência acerca dos conceitos teóricos que norteiam a prática pedagógica a partir de uma perspectiva pragmática. Ter essa consciência é útil não apenas para a desconstrução de mitos relacionados à língua portuguesa que atravessam a sociedade e que habitam os livros didáticos, mas também para o processo de tomada de decisões didático-pedagógicas adequadamente assentadas em conceitos teóricos relevantes para o ensino de português, i.e., conceitos que se encaixam em uma perspectiva pragmática. Assim, abordo questões teóricas essenciais para o ensino da leitura, da escrita e da gramática.

Palavras-chave: Ensino de português; Perspectiva pragmática; Conceitos teóricos; Prática pedagógica.

Abstract: This text is the result of the conference entitled What every Portuguese teacher needs to know, presented at the VIII Meeting of Sociolinguistics - variation and teaching: unity and diversity, which took place at the State University of Bahia, Campus I, in July, 2018. Here I tackle theoretical issues which are unavoidable for Portuguese teachers, which depart from this assertion: there are no pedagogical practices without theories. The objective of this text is to share with the readers some reflections upon the importance of being aware of the theoretical concepts that guide the pedagogical practice from a pragmatic standpoint. Being aware of this is useful not only for the deconstruction of myths related to the Portuguese language which permeate society and inhabit textbooks, but also for the didactic-pedagogical decision making process appropriately based on theoretical concepts which are relevant for Portuguese teaching, i.e., concepts which fit the pragmatic perspective. Therefore, I tackle theoretical issues which are essential for the teaching of reading, writing and grammar.

Keywords: Portuguese teaching; Pragmatic perspective; Theoretical concepts; Pedagogical practice.

\footnotetext{
${ }^{1}$ Professor Associado do Instituto de Letras da Universidade Federal da Bahia. E-mail: lucianoamaral64@yahoo.com
} 


\section{Considerações iniciais}

Foi com surpresa e alegria que recebi o convite da Professora Norma Lopes para proferir uma conferência no VIII Encontro de Sociolinguística, na Universidade Estadual da Bahia. Surpresa, pois transito apenas tangencialmente pelos temas tratados pela sociolinguística. Mas a surpresa se dissipou quando vi o recorte desse Encontro: "variação e ensino". E ensino é a minha principal área de interesse. Daí a alegria, por ter a oportunidade de compartilhar com docentes e, principalmente, com estudantes de Letras algumas reflexões que tenho realizado acerca do ensino de português. São essas reflexões que transponho para o papel, para este texto.

E a primeira reflexão, a partir da qual as outras se originam diz respeito a algo que é fundamental para a labuta pedagógica: não existem práticas docentes às quais não subjazam teorias. A professora e o professor podem até não saber em que concepções teóricas suas práticas se sustentam, mas há, sim, concepções teóricas ali nas suas aulas, nas atividades que levam para a sala de aula, nas informações que fornecem sobre a língua portuguesa, nos livros didáticos que adotam.

Conhecer as teorias que dão sustentação às práticas pedagógicas é triplamente importante.

Em primeiro lugar, as professoras e os professores se tornam mais alertas para os mitos, para os discursos naturalizados que rondam, assombram e atrapalham a prática pedagógica. Por exemplo, o mito da homogeneidade linguística, que divide a sociedade em dois grupos, o das pessoas que sabem português e o daquelas que não sabem português, só pode ser desconstruído a partir dos dados coletados por pesquisadoras e pesquisadores em dialetologia e em sociolinguística, os quais demonstram, inequivocamente, que a língua varia por conta de elementos geográficos, sociais e diafásicos (MONTEAGUDO, 2011). Outro exemplo é o mito segundo o qual a língua portuguesa é machista, que pode ser facilmente desconstruído a partir do estudo sobre as características de uma língua, que pode, dentre outras coisas, ser ou não pró-drop, ser aglutinante ou sintética, ser ou não tonal. O que uma língua não pode ser é machista, nem racista, nem LGBTfóbica, nem indigenofóbica: são as pessoas que podem ter essas facetas identitárias e marcá-las na língua quando a usam.

Em segundo lugar, os livros didáticos só podem ser adequadamente analisados e avaliados por quem domina os conceitos teóricos que os atravessam e os constituem. Por exemplo, se um livro didático traz exercícios de transformação de orações ativas em orações passivas e vice-versa, isso evidencia que sua autora ou seu autor não possuem um conhecimento adequado sobre vozes verbais e sobre agenciamento. Afinal, tal transformação não procede (OLIVEIRA, 2010). Outro exemplo é a naturalização de discursos preconceituosos que podem atravessar o livro didático: é preciso uma análise cuidadosa para identificar as escolhas lexicais e os enunciados que estigmatizam variantes linguísticas e minorias, que naturalizam discursos preconceituosos, para que isso seja problematizado no momento de se adotar um livro didático e no momento de usá-lo.

Em terceiro lugar, conhecer as teorias que sustentam as práticas docentes possibilita que professoras e professores tomem decisões didático-pedagógicas com mais confiança e adequação. Por exemplo, não conhecer a concepção tridimensional da gramática leva professoras e professores a focarem apenas a forma dos elementos gramaticais em detrimento do uso e do significado desses elementos. 
Por essas razões, concentro-me, na próxima seção, em duas concepções teóricas essenciais para as práticas pedagógicas de qualquer área. Na seção seguinte, trato de quatro concepções teóricas especificamente voltadas para o ensino de português.

\section{Duas concepções teóricas essenciais para qualquer prática pedagógica}

Eu cresci ouvindo coisas como "Aquele professor tem muito conhecimento, mas não sabe passar". Infelizmente, ainda hoje, ouvem-se enunciados semelhantes. E por que acabo de usar o advérbio infelizmente? Pelo fato de tais enunciados evidenciarem que ainda existem docentes e estudantes que, conscientemente ou não, concebem o ensino como sendo a transferência de conhecimentos.

Há dois problemas sérios nessa concepção de ensino. O primeiro, que deveria ser óbvio para quem leciona qualquer disciplina, é a impossibilidade de se transferirem conhecimentos de uma pessoa para outra. Se isso fosse verdade, quase todos os problemas relacionados ao ensino estariam resolvidos: bastaria treinar as professoras e os professores a transferirem seus conhecimentos para a cabeça de suas alunas e alunos. O segundo problema é a construção identitária que se impõe a discentes e a docentes: enquanto estes são quem detém os conhecimentos, aqueles são os que nada sabem. A faceta identitária imposta a alunas e alunos é a de seres passivos e ignorantes.

O corolário disso é uma concepção equivocada de aprendizagem que é automaticamente adotada por quem concebe o ensino como transferência de conhecimentos: o behaviorismo. Conforme explico alhures (OLIVEIRA, 2010), quem adota a concepção behaviorista parte do pressuposto de que as alunas e os alunos possuem uma mente vazia, metaforizada pela expressão latina tabula rasa, e, por isso, comportam-se como meras esponjas, absorvendo os conhecimentos transferidos para sua cabeça, e meros papagaios, repetidores que memorizam as informações que lhes são fornecidas.

Não por acaso, Freire (1996) usa o termo concepção bancária da educação para se referir a essas duas concepções. A metáfora bancária capta e sintetiza, de maneira clara e arguta, a concepção de ensino como transferência de conhecimentos e a concepção behaviorista de aprendizagem, as quais são duramente criticadas por Freire (1996). Afinal, professoras e professores não apenas ensinam: também aprendem com suas alunas e alunos, seres dotados de inteligência que precisam se tornar aprendizes autônomos e que assumem a maior parte da responsabilidade pela sua própria aprendizagem. Além disso, como lembra Freire (1996), alunas e alunos não possuem uma mente vazia por já levarem para a sala de aula conhecimentos que construíram a partir das suas leituras do mundo.

Por conta desses problemas, é pedagogicamente mais interessante conceber o ensino como um ato de facilitação da aprendizagem, o que não é algo simples de se fazer. Facilitar a aprendizagem implica oferecer a alunas e alunos atividades pedagógicas significativas, relevantes, voltadas para 0 desenvolvimento de habilidades de uso da língua, lastreadas em princípios teóricos adequados, e realizadas em um ambiente de aprendizagem afetivamente motivador. Isso exige, de professoras e professores, leituras, reflexões e escolhas baseadas em conceitos teóricos pertinentes aos propósitos de suas aulas.

Além disso, conceber o ensino dessa forma implica conceber a aprendizagem como um processo de construção de conhecimentos levado a cabo por alunas e alunos com o auxílio de professoras e 
professores. Essa é a concepção construtivista de aprendizagem, baseada nas ideias de Lev Vygotsky (1995) e Jean Piaget (LEFRANÇOIS, 2009), a qual se apresenta como a mais condizente com a realidade cognitiva dos seres humanos.

Especificamente no que diz respeito ao ensino de português, há quatro concepções teóricas muito importantes, das quais discuto quatro a seguir.

\section{Quatro concepções teóricas inescapáveis para quem ensina português}

Há algumas coisas que precisam estar claras na cabeça de professoras e professores de português e uma delas é exatamente a forma como concebem a língua, i.e., o conceito de língua que adotam. Isso é de extrema importância porque esse conceito vai determinar o eixo em torno do qual suas aulas girarão.

Durante muito tempo, imperou nas salas de aula, sem concorrência, o conceito estruturalista de língua, i.e., um conjunto de estruturas sintáticas, morfológicas, lexicais e fonológicas. Adotando-se esse conceito, o foco das aulas recai sobre a nomenclatura gramatical e sobre as regras gramaticais. Entretanto, essas regras não são aquelas da língua portuguesa que as pessoas usam cotidianamente na oralidade: são aquelas que constam em gramáticas normativas, reproduzidas em livros didáticos e que não fazem parte da realidade linguística cotidiana da maior parte das pessoas por serem regras baseadas na língua usada por escritores literários canônicos. Inevitavelmente, a oralidade e até a leitura e a escrita perdem espaço para a gramática nas aulas de português.

Com o movimento epistemológico conhecido como virada pragmática, que teve início nos anos 1960 e se consolidou na década de 1980 (OLIVEIRA, 2010), linguistas aplicados e professores de língua começaram a enfatizar a importância de se dar foco aos usos que as pessoas fazem da língua. E como a língua em uso se materializa na forma de texto, é ele que, sob a perspectiva pragmática, é o eixo em torno do qual as aulas de português giram.

Dessa forma, quem leciona português passou a ter uma concepção alternativa de língua, que pode ser vista como um conjunto de estruturas sintáticas, morfológicas, lexicais e fonológicas que se materializam na forma de textos durante o processo de interação social, que é cultural e historicamente situado.

Essa concepção interacional de língua é muito mais interessante para o ensino de português. Ela torna a gramática um meio e não um fim, que passa a ser duplo: o desenvolvimento da competência leitora e o desenvolvimento da competência redacional. Além disso, tal concepção contribui para que alunas e alunos entendam que a língua é um fenômeno social, que só existe por meio da interação de, pelos menos, duas pessoas, que colocam em jogo suas facetas identitárias e seus posicionamentos ideológicos durante a interação em um determinado contexto. 0 corolário disso é que essa concepção evidencia o fato de que a língua em uso não é neutra, algo que, se compreendido por alunas e alunos, Ihes ajuda a ter uma postura mais crítica em relação aos textos que leem e ouvem e aos textos que produzem.

Ao adotarem o conceito interacional de língua, sob a perspectiva pragmática, professoras e professores de português inevitavelmente terão de refletir sobre as concepções de leitura, de escrita e de gramática que permeiam as suas práticas pedagógicas. 
Tradicionalmente, a leitura é concebida como o ato de extração de significados de um texto. Isso tem duas implicações importantes. A primeira é a de que a leitura seria uma atividade exclusivamente linguística. Ora, se isso fosse verdade, as pessoas precisariam apenas dominar o código linguístico - mais especificamente as regras sintáticas e o léxico - para ler, ou melhor, para decifrar um texto e o assunto nele contido não colocaria nenhum empecilho para que a leitura ocorresse.

Contudo, a leitura não é uma atividade que exige apenas conhecimentos linguísticos. Para evidenciar isso, apresento o trecho do resumo da tese de mestrado defendida por Goulart Coelho (2009) na área de física nuclear do Instituto Tecnológico da Aeronáutica, em 2009, intitulada Estrelas de quarks no modelo de Nambu-Jona-Lasinio com interações vetoriais.

\begin{abstract}
Neste trabalho estudamos o modelo de Nambu-Jona-Lasinio na versão SU(2) com acoplamento vetorial repulsivo e investigamos a estabilidade da matéria de quarks, realizando um estudo da transição de fase quiral no modelo de NJL em termos de uma análise do potencial termodinâmico do sistema. Para o estudo da estabilidade da matéria de quarks, analisamos o comportamento da pressão e da energia por partícula em função da densidade bariônica. $O$ estado de equilíbrio é determinado como o ponto onde o potencial termodinâmico tem um mínimo, sendo a massa constituinte o parâmetro variacional. Discutimos a influência da interação vetorial na EoS e na estrutura da estrela de quarks. Assumiremos que estas estrelas são compostas de matéria de quark pura com e sem equilíbrio beta, condição esta que não foi considerada nos estudos anteriores e que deve ser obedecida pela matéria no interior de estrelas compactas. Varrendo o intervalo de densidades centrais permitidas pela EoS fornecida pelo modelo NJL na fase de quarks com dois sabores, obtemos relações massa-raio inéditas. [...] (GOULART COELHO, 2009, p. viii)
\end{abstract}

É possível afirmar, com um grau elevado de certeza, que as pessoas que não são da área da física subatômica terão muita dificuldade de entender esse trecho do resumo. Só que tal dificuldade não se deverá à falta de conhecimentos linguísticos, mas, isto sim, à falta de conhecimentos de física subatômica, o que evidencia que a leitura demanda não apenas conhecimentos linguísticos, mas também conhecimentos enciclopédicos, que englobam conhecimentos gerais e conhecimentos específicos de determinadas áreas.

Isso nos leva à segunda implicação de se conceber a leitura como um ato de extração de significados, a qual é exatamente a ideia de que os sentidos de um texto se encontrariam apenas no próprio texto. No frigir dos ovos, essa é uma concepção imanentista do texto, a qual é insustentável. 0 trecho do resumo apresentado anteriormente evidencia que leitoras e leitores produzem sentidos a partir da interação que se estabelece entre, de um lado, as informações, as escolhas lexicais e as escolhas sintáticas que a autora ou o autor, com determinados objetivos, colocam no texto e, do outro lado, os conhecimentos prévios de quem o lê, sem os quais a leitura é algo simplesmente impossível de acontecer.

Assim, percebe-se que é pedagogicamente mais adequado conceber a leitura como um processo dialógico de construção de sentidos que envolve os conhecimentos prévios de quem lê um texto e os elementos linguísticos e as informações nele presentes. Levando isso em consideração, professoras e professores de português podem planejar as aulas de leitura com mais segurança, certificando-se de que suas alunas e seus alunos possuem os conhecimentos prévios necessários para fazerem as leituras propostas nos livros didáticos - se não os possuírem, será necessário ajudar-lhes a construir um mínimo de conhecimentos para que possam realizar as atividades de leitura. 
Da mesma forma que a leitura, a escrita não é uma atividade exclusivamente linguística: ela demanda também conhecimentos enciclopédicos e conhecimentos textuais, que dizem respeito aos gêneros textuais.

É desnecessário argumentar aqui em favor da ideia óbvia de que a escrita demanda conhecimentos linguísticos, mas é preciso comentar acerca do papel que os outros dois tipos de conhecimento exercem no processo da escrita.

Schopenhauer (2005 [1851]), certa vez, afirmou que a primeira regra do bom estilo da escrita, que, por si só, já é quase suficiente, é ter o que dizer. Em outras palavras, mesmo que uma pessoa tenha amplos conhecimentos linguísticos, ela terá dificuldade de redigir um texto sobre um tema que desconhece. Por exemplo, eu não sou capaz de fazer um artigo sobre as formas alotrópicas do hidrogênio a partir da perspectiva quântica de Werner Heisenberg. Outro exemplo é o que aconteceu na edição de 2014 do Exame Nacional do Ensino Médio: 529.374 redações foram zeradas. E a falta de conhecimentos sobre o tema proposto foi a principal a causa desses zeros: a maioria das candidatas e dos candidatos a cujas redações foi atribuída essa nota simplesmente não tinham nada a dizer acerca da publicidade infantil (PIVA, 2017).

E mesmo que uma pessoa domine o tema sobre o qual tem de escrever e tenha um elevado grau de proficiência escrita, ela poderá ter dificuldades para produzir um determinado gênero textual se não o conhecer. Por exemplo, imagine-se uma estudante de graduação em Letras que possui muitos conhecimentos sobre literatura infantil, que escreve de maneira fluente e que decide realizar uma pesquisa sobre esse tema. Inevitavelmente, ela precisará produzir um projeto de pesquisa. Contudo, se não conhecer esse gênero textual, ou seja, sua estrutura, seu objetivo dentro da esfera discursiva acadêmica e o estilo de linguagem que demanda, ela terá dificuldades para realizar essa tarefa, pois terá, primeiro, de aprender a construir um projeto de pesquisa, algo que não é muito simples nem para estudantes de pós-graduação.

Professoras e professores de português precisam levar em consideração se suas alunas e alunos possuem os conhecimentos enciclopédicos e os conhecimentos textuais exigidos para a realização das tarefas de produção textual que lhes atribuem. É para isso que existem as atividades de pré-escrita, que têm como um de seus objetivos determinar se as alunas e os alunos precisarão de mais ou de menos preparação para realizarem a tarefa de produção textual.

Seguindo a perspectiva pragmática, o ensino da gramática não é um fim em si mesmo, mas, isto sim, um meio para que alunas e alunos desenvolvam sua competência leitora e sua competência redacional. Nesse sentido, o ensino da nomenclatura gramatical e o ensino dos elementos gramaticais passam a figurar como elementos secundários nas aulas de português - continuam importantes, enfatizese isso, mas são coadjuvantes no ensino da leitura e no ensino da escrita.

O estudo da nomenclatura gramatical só se justifica se as professoras e os professores tiverem um objetivo prático em mente, qual seja, o desenvolvimento da metalinguagem para as sessões de feedback sobre a produção de textos escritos. Afinal, as alunas e os alunos só podem aprender, por exemplo, a evitar a fragmentação oracional se souberem o que é sujeito e o que é predicado; e só podem aprender a usar a vírgula com segurança se eles conhecerem conceitos teóricos como língua SVO, sujeito, predicado, oração adjetiva restritiva e oração adjetiva explicativa (vale lembrar que a vírgula não indica 
pausa). Dar aulas sobre a nomenclatura gramatical objetivando-se apenas que alunas e alunos memorizem conceitos é extremamente inútil e injustificável.

Quanto ao ensino dos elementos gramaticais, professoras e professores precisam decidir de que maneira concebem a gramática, pois sua decisão terá implicações importantes nas suas aulas. $\mathrm{E}$ há duas concepções possíveis do ponto de vista pedagógico: a unidimensional e a tridimensional.

Adotar-se a concepção unidimensional da gramática implica considerar apenas a forma, a estrutura dos elementos gramaticais. E, tradicionalmente, essa é a concepção adotada por muitas professoras e muitos professores de português no Brasil, que acabam levando suas alunas e alunos a se concentrarem exclusivamente na forma do elemento gramatical. Tal concepção é muito limitadora e dois exemplos bastam para ilustrar isso.

Pensemos no caso dos pronomes. Eles são elementos de coesão por excelência, estabelecendo relações de referência anafórica e catafórica entre elementos que compõem o texto. Isso posto, eu pergunto: qual é a maneira mais lógica e óbvia de se trabalhar com eles em sala de aula? Por meio de textos, pois é nos textos que os pronomes realizam suas funções coesivas. Os pronomes não existem fora de textos.

No entanto, ainda há professoras e professores que dão mais foco à nomenclatura dos pronomes, usando aquele quadro tradicional apresentado em gramáticas normativas em que figuram tu e vós, e ignorando o contexto em que suas alunas e alunos se encontram.

Permita-me, leitora ou leitor, usar a cidade em que moro, Salvador, como base para um exemplo. Em nossa terra, não se usa vós e apenas pessoas oriundas de outras cidades usam o tu. Por isso, o quadro pronominal do português falado em minha cidade é composto destes elementos:

SINGULAR PLURAL $\begin{aligned} & e u \\ & \text { você, cê } \\ & \text { ela, ele, se }\end{aligned} \quad\left\{\begin{array}{l}\text { nós, a gente } \\ \text { vocês, cê } \\ \text { elas, eles, se }\end{array}\right.$

Com base nisso, uma pergunta é inevitável: por que uma professora ou um professor de português, em Salvador, deveriam iniciar o ensino de pronomes focando aquele quadro que consta nas gramáticas normativas, enfatizando a nomenclatura, ignorando a função textual dos pronomes e a realidade linguística de suas alunas e alunos? Não faz sentido um ensino assim.

O segundo exemplo que ilustra a limitação pedagógica inerente à concepção unidimensional de gramática diz respeito às vozes verbais. De que adianta dar aulas sobre a voz passiva e a voz ativa e levar para a sala aquelas atividades mecânicas, equivocadas e inúteis de transformação de orações ativas em orações passivas e vice-versa? Nessas atividades, foca-se em transformações como a do objeto direto da oração ativa em sujeito-paciente da oração passiva. Contudo, essas transformações não procedem, pois a oração passiva é sintaticamente independente da oração ativa, i.e., aquela não deriva desta.

Quem descobriu esse fato e viveu um dilema por conta da descoberta foram as pesquisadoras e os pesquisadores gerativistas no final da fase em que imperou a Teoria Standard. Noam Chomsky havia estabelecido que a oração passiva seria resultante da aplicação de regras transformacionais sobre a 
estrutura profunda de uma oração ativa. Ele defendia também a ideia de que o significa era determinado na estrutura profunda e que as transformações não alteravam esse significado durante a geração da estrutura superficial. O problema é que Chomsky e seus seguidores se depararam com o caso das orações que possuem dois quantificadores em uma oração ativa (e.g. "Todos nesta cidade falam duas línguas.") e que têm sua ordem alterada se essa oração for transformada em ativa (e.g. "Duas línguas são faladas por todos nesta cidade".) e perceberam que as orações desse tipo possuem significados completamente diferentes. A não correspondência semântica entre a voz passiva e a voz ativa criou um racha. Uma parte das pesquisadoras e pesquisadores gerativistas concluiu que a oração passiva e a oração ativa são estruturas independentes e abandonaram a ideia de que uma oração na voz passiva deriva de uma oração na voz ativa; a outra parte continuou achando que uma deriva da outra, mas abriram mão do princípio arbitrário - de que a aplicação das regras transformacionais não alteram o significado da estrutura profunda, o que permitira que as regras de interpretação semântica operassem em níveis diferentes e não apenas na estrutura profunda (LOBATO, 1986).

Ora, apesar do dito popular "toda regra tem exceção", teorias não suportam exceções. Quando surge algo que seria uma exceção a regras estabelecidas por uma teoria, isso significa que a teoria tem de ser abandonada e uma nova, construída. E o fato é que as orações na voz passiva não derivam das orações na voz ativa.

Portanto, as atividades de transformação de orações na voz ativa para orações na voz passiva e vice-versa são embasadas em um equívoco teórico e, por isso, são inúteis. O que fazer, então, para se ensinar a voz passiva, os pronomes e outros elementos gramaticais de maneira adequada e significativa?

A solução é seguir a perspectiva pragmática e adotar a concepção tridimensional de gramática proposta por Celce-Murcia e Larsen-Freeman (1999), segundo a qual os elementos gramaticais possuem uma dimensão formal, que diz respeito à estrutura do elemento; uma dimensão semântica, que diz respeito ao seu significado; e uma dimensão pragmática, que diz respeito aos usos que se fazem do elemento.

Ao analisarem tridimensionalmente um elemento gramatical que será foco da sua aula, professoras e professores podem determinar qual dimensão ou quais dimensões são desafiadoras para suas alunas e alunos. No caso da voz passiva, por exemplo, a dimensão formal não é problema para nenhuma pessoa falante de português. $O$ desafio reside na dimensão pragmática: saber usar a voz passiva implica saber que contextos discursivos e, consequentemente, que gêneros textuais favorecem a sua ocorrência.

Quanto ao ensino dos pronomes, percebe-se que, seguindo-se a concepção tridimensional, o desafio se encontra no seu uso. As alunas e os alunos precisam aprender a reconhecer e a realizar referências anafóricas e catafóricas estabelecidas pelos pronomes dentro de um texto. Além disso, precisam aprender a escolher os pronomes de acordo com o grau de formalidade da situação em que produzem textos orais e textos escritos: nós ou a gente; você ou cê. Finalmente, precisam de orientação acerca de vós, usado apenas em romances, contos e poemas publicados há algumas décadas e em alguns gêneros textuais religiosos. 


\section{Considerações finais}

Do exposto até aqui, fica claro que professoras e professores de português precisam ter consciência das concepções teóricas que lastreiam a sua prática pedagógica. É essa consciência que lhes ajuda a tomar decisões coerentes no que diz respeito à escolha de materiais e de livros didáticos e ao tipo de atividades que levam para a sala de aula.

Além disso, ter consciência teórica é essencial para a construção identitária de professoras e professoras, que precisam responder a uma pergunta importante: "Que tipo de docente eu quero ser?".

E o leque de facetas identitárias que podem escolher é grande: docente que usa o livro ou que é usado por ele; que concebe o ensino como transferência de conhecimentos ou que o concebe como facilitação da aprendizagem; que vê as alunas e alunos como seres inteligentes ou que os vê como seres passivos com mentes vazias a serem moldadas; que concebe a escrita e a leitura como atividades exclusivamente linguísticas ou que as vê como processos dialógicos de construção de sentidos.

No frigir dos ovos, o que toda professora e todo professor de português precisam saber é que tipo de docente querem ser.

\section{Referências}

CELCE-MURCIA, Marianne; LARSEN-FREEMAN, Diane. The grammar book: an ESL / EFL course. 2. ed. Estados Unidos: Heinle \& Heinle, 1999.

FREIRE, Paulo. Pedagogia do oprimido. 23 ed. São Paulo: Paz e Terra, 1996.

GOULART COELHO, Jaziel. Estrelas de quark no modelo de Nambu-Jona-Lasinio com interações vetoriais. 2009. 140 f. Dissertação (Mestrado) - Curso de Física. Área de Física Nuclear - Instituto Tecnológico da Aeronáutica, 2009.

LEFRANÇOIS, Guy. Teorias da aprendizagem. Trad.: Vera Magyar. São Paulo: Cengage, 2009. Título original: Theories of human learning: what the old woman said.

LOBATO, Lucia Maria Pinheiro. Sintaxe gerativa do português da teoria padrão à teoria da regência e ligação. Belo Horizonte: Vigília, 1986.

MONTEAGUDO, Henrique. Variação linguística: subsídios para uma (re)visão. In: LAGARES, Xoán; BAGNO, Marcos (orgs.). Políticas da norma e conflitos linguísticos. São Paulo: Parábola Editorial, 2011. p. 15-48.

OLIVEIRA, Luciano Amaral. Coisas que todo professor de português precisa saber: a teoria na prática. São Paulo: Parábola, 2010.

PIVA, Naiady. Notas zero refletem mudanças no Enem. Disponível em: <http://www.gazetadopovo.com.br/educacao/notas-zero-refletem-mudancas-no-enemej0sgsqo7ih6ghwqwn1lcwila>. Acesso em: 12 fev. 2017.

SCHOPENHAUER, Arthur. Sobre o ofício do escritor. Tradução de Eduardo Brandão. 2. ed. São Paulo: Martins Fontes, 2005 [1851]. Título original: Über Schrifstellerei und Stil.

VYGOTSKY, Lev. S. Pensamento e linguagem. Trad.: Jeferson Luiz Camargo. São Paulo: Martins Fontes, 1995. Título original: Thought and language. 